\title{
Downregulation of Dock1 and Elmo1 suppresses the migration and invasion of triple-negative breast cancer epithelial cells through the RhoA/Rac1 pathway
}

\author{
YUEYANG LIANG, SHUSHU WANG and YI ZHANG \\ Breast Disease Center, Southwest Hospital, Army Medical University, Chongqing 400038, P.R. China
}

Received December 5, 2017; Accepted May 11, 2018

DOI: $10.3892 / \mathrm{ol} .2018 .9077$

\begin{abstract}
Dedicator of cytokinesis 1 (Dock1), a guanine nucleotide exchange factor, has been proven to facilitate cell survival, motility and proliferation via the activation of Ras-related C3 botulinum toxin substrate 1 (Rac1). Engulfment and cell motility 1 (Elmo1) serves as a mammalian homolog of Ced-12, which has been evolutionarily conserved from worm to human. The present study aimed to investigate the roles and mechanisms of Dock1 and Elmol in the migration and invasion of triple-negative breast cancer (TNBC) epithelial cells. Cell Counting kit-8, cell migration and cell invasion assays were performed to assess cell viability, migration and invasion, respectively. A plate clone formation assay was performed to determine cell proliferation. Western blot analysis and reverse transcription-quantitative polymerase chain reaction (RT-qPCR) assays were used to evaluate mRNA and protein expression. The results revealed that the downregulation of Dock1 and Elmo1 inhibited cell viability, suppressed migration and invasion, and reduced Rac1 activity in MDA-MB-231 cells. Furthermore, downregulation of Dock1 and Elmo1 also attenuated the expression of migration-associated proteins and affected the Ras homolog gene family, member A (RhoA)/Rac1 pathway in MDA-MB-231 cells. In conclusion, the results of the present study suggested that the downregulation of Dock1 and Elmol suppresses the migration and invasion of TNBC epithelial cells through the RhoA/Rac1 pathway.
\end{abstract}

\section{Introduction}

Breast cancer, one of the most prevalent types of malignant tumor in females, severely impairs the health of females

Correspondence to: Dr Yi Zhang, Breast Disease Center, Southwest Hospital, Army Medical University, 30 Gaotanyan Main Street, Chongqing 400038, P.R. China

E-mail: yizhang922zy@163.com

Key words: dedicator of cytokinesis 1, engulfment and cell motility 1, triple-negative breast cancer, migration, invasion, Ras homolog gene family, member A, Ras-related C3 botulinum toxin substrate 1, focal adhesion kinase, Talin, Vinculin worldwide $(1,2)$. Breast cancer is generally classified into five subtypes, including luminal type A, luminal type B, normal breast type, human epidermal growth factor receptor-2 (HER2) overexpression type and basal type (3). For clinical treatment and prognostic evaluation, it is conventional to assess the expression of three breast cancer markers, including estrogen receptor (ER), progesterone receptor (PR) and HER2, by immunohistochemistry, hence the concept of triple-negative breast cancer (TNBC) (4). TNBC refers to breast cancer with negative immunohistochemical results for ER, PR and HER2, and acts as a specific breast cancer subtype, which was proposed in recent years (5). Specific characteristics of TNBC include high invasiveness and metastasis, high recurrence and mortality rates, and a low survival rate. However, the exact molecular mechanisms of TNBC remain unclear.

Rho-family GTPases, a primary branch of the Ras superfamily of small GTPases, including RhoA and Ras-related C3 botulinum toxin substrate 1 (Rac1), are identified as crucial regulators of actin cytoskeleton dynamics and endothelial contractions (6). Deregulation of these Rho-GTPases may result in a disorder of the actin cytoskeleton and may further impact the integrity of the endothelial barrier. Previous studies have demonstrated that deregulated Rho-GTPases are associated with the development and progression of various types of tumor, including testicular cancer (7), colorectal tumors (8), gastric carcinoma (9) and breast cancer (10). Nevertheless, the precise role of these signaling mechanisms in the migration and invasion of TNBC cells is not well understood.

Dedicator of cytokinesis 1 (Dock1), a guanine nucleotide exchange factor, has been proven to facilitate cell survival, motility and proliferation via the activation of $\operatorname{Rac1}(11,12)$. Engulfment and cell motility 1 (Elmo1) serves as a mammalian homolog of Ced-12, which has been evolutionarily conserved from worm to human. Elmo1 itself has no intrinsic catalytic activity, but can regulate the activity of interacting proteins as a scaffold protein (13). Furthermore, Elmol also joins multiple cellular processes, including myoblast fusion, neurite outgrowth, phagocytosis of apoptotic cells and cell migration (14). Additionally, previous studies have demonstrated that by interacting with Dock1, Elmo1 acts as an element of a bipartite guanine nucleotide-exchange factor for Rac1 (15-20). Recently, it was revealed that the interaction between Dock1 and Elmol could modulate tumor metastasis, which is enhanced by the actin cytoskeleton in breast cancer (21). Therefore, Dock1 
and Elmo1 were selected as the objects of the present study, in order to determine their exact roles and mechanisms in the migration and invasion of TNBC epithelial cells.

The present study analyzed the association between Dock1, Elmo1 and the migration and invasion of TNBC epithelial cells. Furthermore, the roles and mechanisms of Dock1 and Elmo1 were investigated, together with those of the RhoA/Racl pathway in the migration and invasion of TNBC epithelial cells.

\section{Materials and methods}

Cell culture. The human TNBC epithelial MDA-MB-231 cell line was obtained from the Type Culture Collection of the Chinese Academy of Sciences (Shanghai, China). Cells were maintained in Dulbecco's modified Eagle's medium (DMEM; Gibco; Thermo Fisher Scientific, Inc., Waltham, MA, USA) supplemented with $10 \%$ fetal bovine serum (FBS; Gibco; Thermo Fisher Scientific, Inc.), in a $5 \% \mathrm{CO}_{2}$ atmosphere at $37^{\circ} \mathrm{C}$.

Cell transfection. Dock1 siRNA (targeting sequence: 5'-GGC CTACACTTTGCTTCTGC-3'), Elmol siRNA (targeting sequence: 5'-CGACAAUGUAACUCUGCAA-3') and unspecific scrambled siRNA (50 nM) (targeting sequence: 5'-ACG UGACACGUUCGGAGAATT-3') vectors (Invitrogen; Thermo Fisher Scientific, Inc.) were transfected into MDA-MB-231 cells using Lipofectamine ${ }^{\circledR} 2000$ (Invitrogen; Thermo Fisher Scientific, Inc.) at $37^{\circ} \mathrm{C}$ for $48 \mathrm{~h}$. Subsequent experiments were performed $48 \mathrm{~h}$ after transfection.

Grouping. In the present study, there were four treatment groups, including the control group (MDA-MB-231 cells), NC group (MDA-MB-231 cells transfected with unspecific scrambled siRNA vector), si-Dock1 group (MDA-MB-231 cells transfected with Dock1 siRNA vector) and si-Elmo1 group (MDA-MB-231 cells transfected with Elmol siRNA vector).

Cell viability analysis. The viability of MDA-MB-231 cells was assessed by the Cell Counting kit-8 (CCK-8; Beyotime Institute of Biotechnology, Haimen, China). MDA-MB-231 cells $\left(\sim 6 \times 10^{4}\right.$ cells $\left./ \mathrm{ml}\right)$ in the logarithmic phase were plated into the wells of 96-well plates, prior to being incubated in a $5 \% \mathrm{CO}_{2}$ atmosphere at $37^{\circ} \mathrm{C}$ for $12 \mathrm{~h}$. Cells were then treated with one of the four aforementioned treatments. Subsequently, cells were maintained for 12,24 or $48 \mathrm{~h}$. Subsequently, $10 \mu \mathrm{l}$ CCK reagent were added into each well and cells were maintained for $3 \mathrm{~h}$. A microplate reader (Bio-Rad Laboratories, Inc., Hercules, CA, USA) was used to read the absorbance at $450 \mathrm{~nm}$. Cell viability was evaluated by the percentage of live cells compared with the control.

Invasion and migration assay. Transwell assays were used to detect the migration and invasion of cells. Matrigel inserts were used in the invasion assay, and not the migration assay. Otherwise, the protocols were identical for both assays. A 24-well Transwell chamber ( $8 \mu \mathrm{m}$; Corning Incorporated, Corning, NY, USA) coated with Matrigel (BD Biosciences, Franklin Lakes, NJ, USA) was used. Cultured MDA-MB-231 cells were suspended in serum-free DMEM (100 $\mu 1$;
Gibco; Thermo Fisher Scientific, Inc.) and maintained for $24 \mathrm{~h}$. Cells $\left(2 \times 10^{4}\right.$ cells $\left./ \mathrm{ml}\right)$ were then placed on the upper Transwell chamber, and the lower chamber was filled with DMEM supplemented with 10\% FBS as chemoattractant. Following incubation for $24 \mathrm{~h}$, the cells that had invaded into the lower chamber were fixed with $4 \%$ paraformaldehyde (Sigma-Aldrich; Merck KGaA, Darmstadt, Germany) at room temperature for $10 \mathrm{~min}$ and stained with $0.5 \%$ crystal violet (Beijing Solarbio Science \& Technology Co., Ltd.) at room temperature for $30 \mathrm{~min}$. The number of invaded cells was counted visually under a fluorescence microscope (magnification, x200; Olympus Corporation, Tokyo, Japan).

Plate colony formation assay. Cultured MDA-MB-231 cells in the logarithmic phase were digested by $0.25 \%$ trypsin (Gibco; Thermo Fisher Scientific, Inc.), and then suspended in DMEM supplemented with 10\% FBS (Gibco; Thermo Fisher Scientific, Inc.). The cell suspension $\left(\sim 6 \times 10^{4}\right.$ cells $\left./ \mathrm{ml}\right)$ was then inoculated in the culture dishes, which were incubated in a $5 \% \mathrm{CO}_{2}$ atmosphere at $37^{\circ} \mathrm{C}$ for 2 weeks. Subsequently, the supernatant was discarded and cells were washed twice with PBS. Next, the cells were incubated with $5 \mathrm{ml} 4 \%$ paraformaldehyde for $15 \mathrm{~min}$. The supernatant was then discarded and Giemsa stain (Beijing Solarbio Science \& Technology Co., Ltd.) was added for $30 \mathrm{~min}$ at room temperature. Finally, cells were washed with PBS and air-dried. The number of cell colonies was counted visually using a fluorescence microscope (magnification, x200).

Western blot analysis. The protein of cells was extracted using radioimmunoprecipitation assay buffer (Beyotime Institute of Biotechnology). The bicinchoninic acid method was applied to assess the concentration of protein. Protein lysates $(35 \mu \mathrm{g}$ ) of cultured MDA-MB-231 cells were separated by $12 \%$ SDS-PAGE. Subsequently, the separated products were transferred to polyvinylidene difluoride membranes (EMD Millipore, Billerica, MA, USA). TBST containing 5\% skim milk was used out to block the membranes at $37^{\circ} \mathrm{C}$ for $60 \mathrm{~min}$. Western blotting was performed using the following specific antibodies: Rabbit anti-human anti-Dock1 (dilution, 1:1,000; catalog no. ab97325; Abcam, Cambridge, UK), rabbit anti-human anti-Elmo1 (dilution, 1:10,000; catalog no. ab174298; Abcam), rabbit anti-human anti-FAK (dilution, 1:1,000; catalog no. ab40794; Abcam), rabbit anti-human anti-Talin (dilution, 1:1,000; catalog no. ab71333; Abcam), rabbit anti-human anti-Vinculin (dilution, 1:10,000; catalog no. ab129002; Abcam), rabbit anti-human anti-RhoA (dilution, 1:5,000; catalog no. ab187027; Abcam), rabbit anti-human anti-Rac1 (dilution, 1:1,000; catalog no. ab155938; Abcam) and rabbit anti-human anti-actin (dilution, 1:5,000; catalog no. ab179467; Abcam). A horseradish peroxidase-conjugated secondary antibody (goat anti-mouse IgG-HRP; catalog no. sc-2005; dilution, 1:6,000; donkey anti-goat IgG-HRP; cat. no. sc-2020; dilution, 1:7,000; Santa Cruz Biotechnology, Inc., Dallas, TX, USA) were added, and the membranes were incubated at room temperature for $1 \mathrm{~h}$. Enhanced chemiluminescent reagents (EMD Millipore, Billerica, MA, USA) were added and an enhanced chemiluminescence system (GE Healthcare, Chicago, IL, USA) was used for evaluating the results. The blots were visualized by Gel documentation 
analyzer (Bio-Rad Laboratories, Inc.) and densitometry was performed using Quantity One 1-D software (version 4.62; Bio-Rad Laboratories, Inc.).

Reverse transcription-quantitative polymerase chain reaction $(R T-q P C R)$. Total RNA was extracted from cultured MDA-MB-231 cells using TRIzol reagent (Beijing Solarbio Science \& Technology Co., Ltd.). RNA was reverse transcribed to cDNA using a Reverse Transcription kit (Beijing Solarbio Science \& Technology Co., Ltd.), according to the manufacturer's protocols. The cDNA was amplified using SYBR Green qPCR Master Mix (MedChenExpress, Monmouth Junction, NJ, USA). RT-qPCR analysis was performed using an ABI 7500 Thermocycler (Applied Biosystems; Thermo Fisher Scientific, Inc.). The thermocycling conditions were as follows: $10 \mathrm{~min}$ pre-treatment at $94^{\circ} \mathrm{C}, 97^{\circ} \mathrm{C}$ for $15 \mathrm{sec}$, $64^{\circ} \mathrm{C}$ for $45 \mathrm{sec}(45 \mathrm{cycles}), 97^{\circ} \mathrm{C}$ for $15 \mathrm{sec}, 64^{\circ} \mathrm{C}$ for $1 \mathrm{~min}$, $94^{\circ} \mathrm{C}$ for $15 \mathrm{sec}$, and a final extension at $75^{\circ} \mathrm{C}$ for $10 \mathrm{~min}$. The primers were designed by Invitrogen; Thermo Fisher Scientific, Inc.: Dock1 forward, 5'-CCGCCGCAAACTTTT TCCTC-3' and reverse, 5'-AGATGTGCACAGTGTCTCCG-3' (product: $222 \mathrm{bp}$ ); Elmo1 forward, 5'-GTAGGGACCCTT CTAGCTGC-3' and reverse, 5'-GCTCAGGTTCTGCAGTTT GC-3' (product: 202 bp); FAK forward, 5'-GAGCGTCTAATC CGACAGCA-3' and reverse, 5'-GGATTTCTTTCCGCCCAA TTCT-3' (product: 209 bp); Talin forward, 5'-TAGCCTGAA AGGGAACTCGG-3' and reverse, 5'-CTTCCGTCCTGG GAACGTC-3' (product: 206 bp); Vinculin forward, 5'-GCA AAAGCTGTGGCTGGAAA-3' and reverse, 5'-ATGTCATTG CCCTTGCTGGA-3' (product: 356 bp); actin forward, 5'-GAT ATTGGCAACGACCCCCA-3' and reverse, 5'-CCCAGCCAG GATCTTGAAGG-3' (product: $174 \mathrm{bp}$ ). Actin was used as the control of the input RNA level. Data were quantified using the $2^{-\Delta \Delta \mathrm{Cq}}$ method (22).

Statistical analysis. The statistical analyses were performed using SPSS software (version 19.0; IBM Corp, Armonk, NY, USA). The results of the present study are presented as the mean \pm standard error of the mean of at least three independent experiments. All experimental data were analyzed using a one-way analysis of variance and the post-hoc test was Fisher's least significant difference test. $\mathrm{P}<0.05$ was considered to indicate a statistically significant difference.

\section{Results}

Downregulation of Dockl and Elmol inhibits the viability of $M D A-M B-231$ cells. siRNA vectors targeting Dock1 and Elmo1, si-Dock1 and si-Elmol, were constructed in the present study. The knockdown efficiency was $\sim 45$ and $70 \%$ in MDA-MB-231 cells, following stable transfection with si-Dock1 and si-Elmo1, respectively (Fig. 1A). Additionally, the western blot analysis results indicated that following transfection with si-Dock1, the expression levels of Dock1 and Elmo1 proteins in MDA-MB-231 cells were significantly reduced $(\mathrm{P}<0.01$; Fig. 1B). Furthermore, following transfection with si-Elmo1, the expression levels of Dock1 and Elmo1 proteins in MDA-MB-231 cells were significantly downregulated $(\mathrm{P}<0.05$; Fig. 1B). Therefore, it was confirmed that interfering with the Dock1 and Elmol genes could simultaneously impact the expression levels of Dock1 and Elmo1 in MDA-MB-231 cells, which indicated that there is an interaction between Dock1 and Elmo1. Therefore, the CCK-8 assay was performed to measure the viability of MDA-MB-231 cells in the aforementioned treatment groups. The results demonstrate that, compared with the control and NC groups, the viability of MDA-MB-231 cells transfected with si-Dock1 and si-Elmo1, for 24 and $48 \mathrm{~h}$, was significantly reduced $(\mathrm{P}<0.05$; Fig. $2 \mathrm{~A}$ ). Subsequently, the proliferation of MDA-MB-231 cells in the four treatment groups was assessed. Compared with the NC group, significant decreases in proliferation capacity were observed in MDA-MB-231 cells transfected with si-Dock1 and si-Elmol $(\mathrm{P}<0.05$; Fig. $2 \mathrm{~B})$. Taken together, these results suggested that the downregulation of Dock1 and Elmo1 inhibited the viability of MDA-MB-231 cells.

Downregulation of Dockl and Elmol suppresses the migration and invasion of $M D A-M B-231$ cells. The migration and invasion capacities of MDA-MB-231 cells were also evaluated in the present study. The results of the migration assay revealed that the migration ability of MDA-MB-231 cells transfected with si-Dock1 and si-Elmo1 was significantly weaker than that of the NC group, decreasing from 95.84 to $20.51 \%$ and $42.61 \%$, respectively ( $\mathrm{P}<0.01$; Fig. $3 \mathrm{~A})$. A similar trend was also observed in the invasion ability of MDA-MB-231 cells transfected with si-Dock1 and si-Elmo1, which decreased from 82.61 to $35.22 \%$ and $52.64 \%$, respectively $(\mathrm{P}<0.05$; Fig. $3 \mathrm{~B})$. Therefore, it was confirmed that the downregulation of Dock1 and Elmo1 decreased the migration and invasion abilities of MDA-MB-231 cells.

Downregulation of Dock1 and Elmol reduced Racl activity and the expression of migration-associated proteins in $M D A-M B-231$ cells. In the present study, the associated migration mechanisms and Racl activity in MDA-MB-231 cells were also assessed. The results revealed that Rac1 activity in MDA-MB-231 cells was significantly reduced by transfecting with si-Dock1 and si-Elmo1 ( $\mathrm{P}<0.01$; Fig. 4A). Additionally, the expression levels of migration-associated proteins, including focal adhesion kinase (FAK), Talin, and Vinculin, in MDA-MB-231 cells were measured. The RT-qPCR results demonstrated that Dock1 and Elmo1 silencing significantly decreased the expression levels of FAK, Talin and Vinculin in MDA-MB-231 cells $(\mathrm{P}<0.05$; Fig. 4B). Furthermore, western blotting results also revealed similar trends in the levels of migration-associated proteins in MDA-MB-231 cells from each treatment group (Fig. 4C). Based on these results, it was concluded that the downregulation of Dock1 and Elmol decreased Rac1 activity and reduced the migration and invasion abilities of MDA-MB-231 cells by downregulating the expression of FAK, Talin and Vinculin.

Downregulation of Dockl and Elmol affects the RhoA/Racl pathway. Finally, the expression of RhoA GTPase, total RhoA, Rac1 GTPase and total Rac1 was evaluated in MDA-MB-231 cells from all four treatment groups. Western blotting results indicated that the expression level of RhoA GTPase in MDA-MB-231 cells was significantly upregulated by transfecting with si-Dock1 

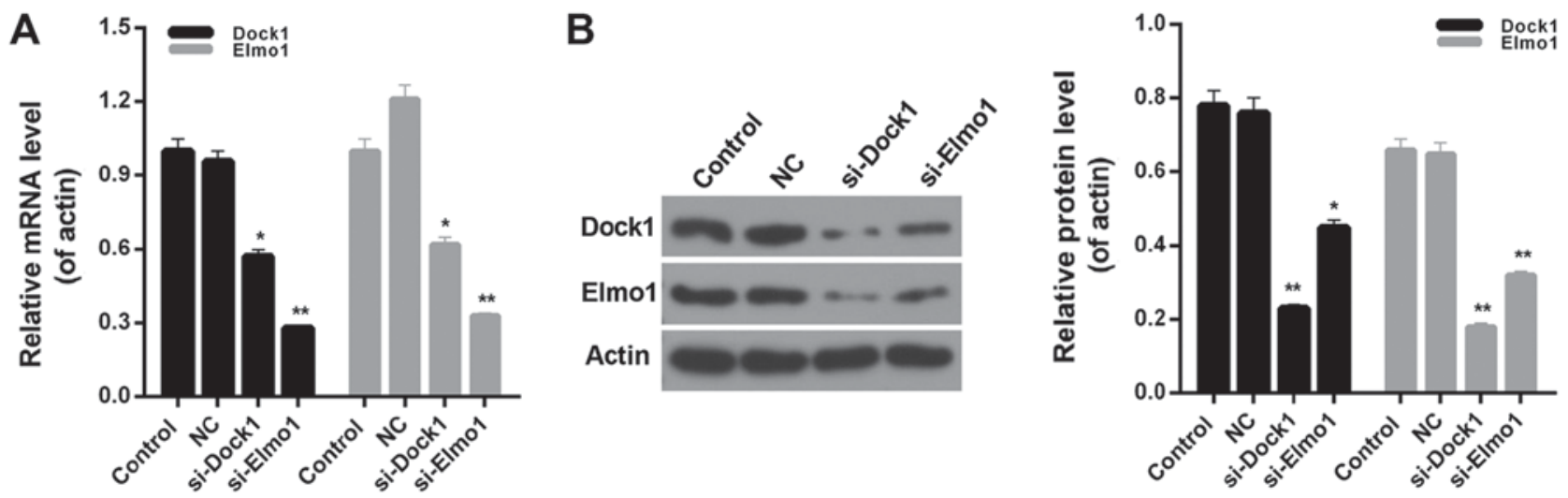

Figure 1. Interaction between Dock1 and Elmo1.(A) Reverse transcription-quantitative polymerase chain reaction and (B) western blot analysis were performed on the expression levels of Dock1 and Elmo1 in MDA-MB-231 cells, MDA-MB-231 cells transfected with an empty vector, MDA-MB-231 cells transfected with si-Dock1 and MDA-MB-231 cells transfected with si-Elmo1. ${ }^{*} \mathrm{P}<0.05$ and ${ }^{* *} \mathrm{P}<0.01$ vs. NC. Dock1, dedicator of cytokinesis 1; Elmo1, engulfment and cell motility 1; si, small interfering RNA; NC, negative control.
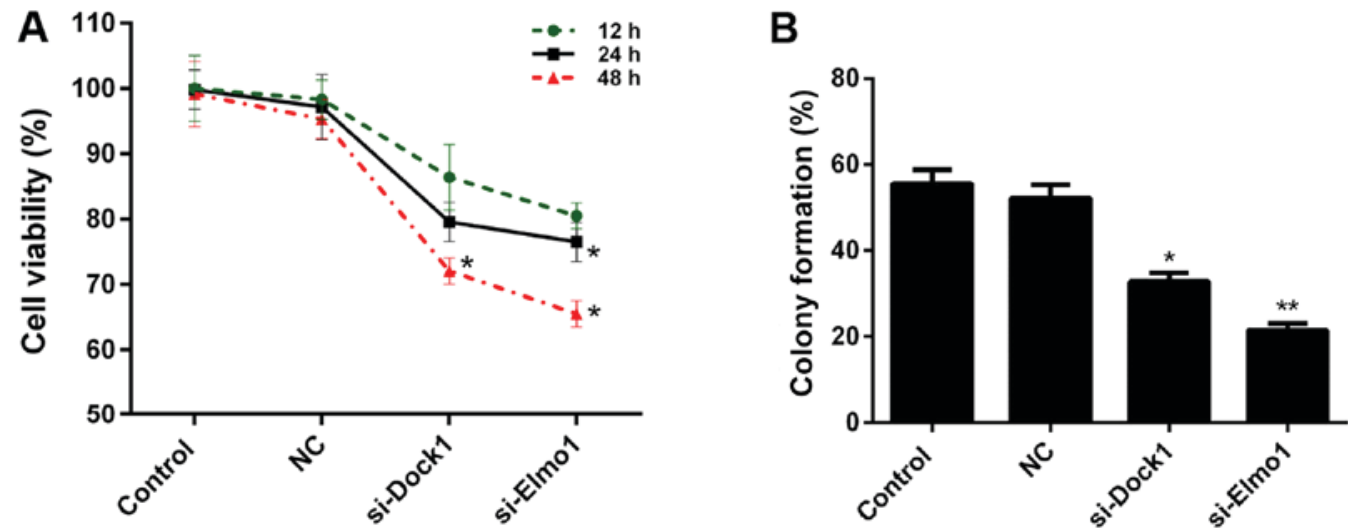

Figure 2. Downregulation of Dock1 and Elmo1 inhibits the viability of MDA-MB-231 cells. (A) Cell Counting kit-8 and (B) plate colony formation assays were performed to measure the viability of MDA-MB-231 cells, MDA-MB-231 cells transfected with an empty vector, MDA-MB-231 cells transfected with si-Dock1 and MDA-MB-231 cells transfected with si-Elmol. ${ }^{*} \mathrm{P}<0.05$ and ${ }^{* *} \mathrm{P}<0.01$ vs. NC. Dock1, dedicator of cytokinesis 1; Elmo1, engulfment and cell motility 1; si, small interfering RNA; NC, negative control.

and si-Elmo1 ( $\mathrm{P}<0.01$; Fig. 5A). Additionally, it was also revealed that the downregulation of Dock1 and Elmo1 significantly reduced the expression level of Rac1 GTPase in MDA-MB-231 cells (Fig. 5B; $\mathrm{P}<0.001$ ). However, there was no significant difference in the total RhoA and total Rac1 expression in MDA-MB-231 cells from all treatment groups (Fig. 5A and B). Therefore, it was concluded that the downregulation of Dock1 and Elmo1 affected the RhoA/Rac1 pathway in MDA-MB-231 cells.

\section{Discussion}

A previous study has demonstrated that Dock1 and Elmol are highly expressed in invasive cancer cells, accelerating cancer progression (23). In addition, an increasing volume of evidence has revealed that the silencing of Dock1 and Elmol can impede tumor development, including cell proliferation, invasion and migration $(17,24,25)$. To the best of our knowledge, the roles of Dock1 and Elmol in the prevention and treatment of TNBC have not yet been studied. In the present study, plasmids cloned with si-Dock1 and si-Elmo1 were prepared. The knockdown efficiency was $\sim 45$ and $70 \%$ in the MDA-MB-231 cells, following stable transfection with si-Dock1 and si-Elmo1, according to the RT-qPCR and western blot analysis data. Additionally, an interaction between Dock1 and Elmo1 was identified, which was consistent with the results of previous studies (15-20). Therefore, the present study further assessed the influences of Dock1 and Elmo1 on cell proliferation. The results revealed that the downregulation of Dock1 and Elmo1 significantly inhibited the proliferation of MDA-MB-231 cells.

Cell motility is important for the majority of pathological and physiological processes, including early embryonic development, wound repair, and tumor cell migration and invasion (26). Previous studies have demonstrated that Dock1 and Elmol serve crucial roles in the migration and invasion of various types of tumor cells $(23,27-29)$. Therefore, the effects of Dock1 and Elmo1 on the migration and invasion capacities of MDA-MB-231 cells were assessed. The results indicated that the downregulation of Dock1 and Elmol could significantly decrease the migration and invasion abilities of MDA-MB-231 cells.

Furthermore, by using the Transwell chamber assay, it was demonstrated that Dock1 and Elmo1 synergistically promote the Rac-dependent cell migration process (24). 
A

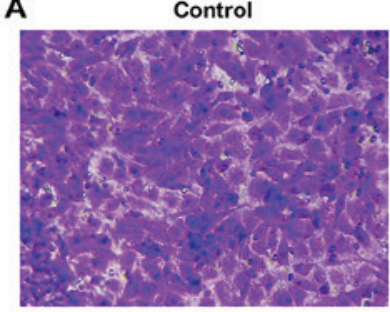

si-Dock1
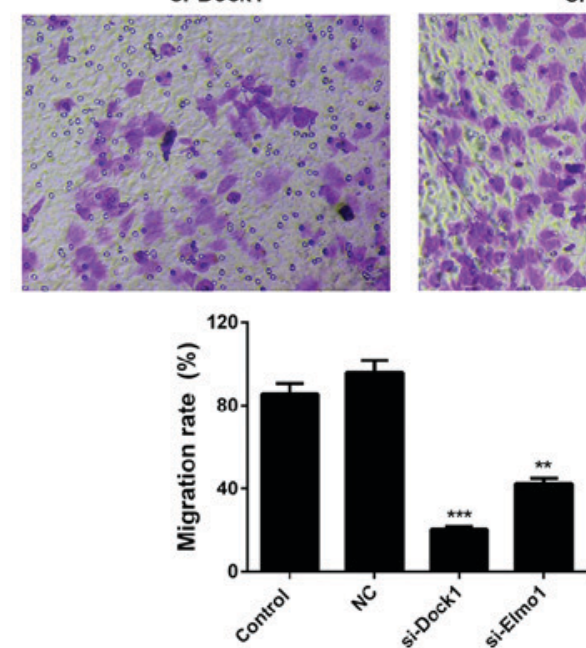

B

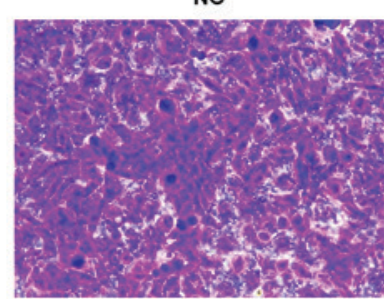

si-Elmo1
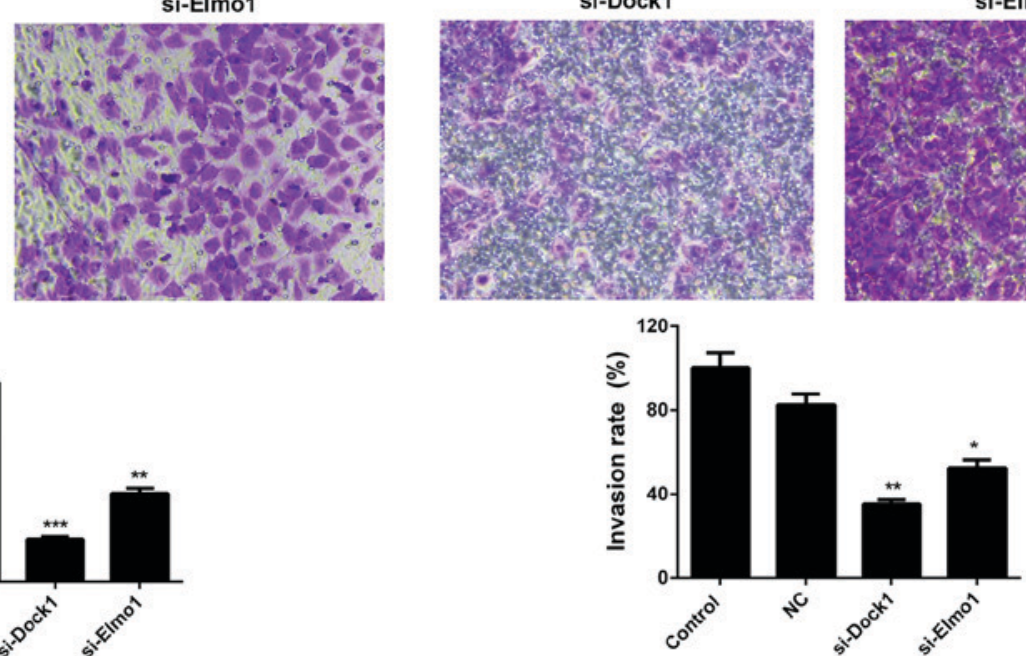

Figure 3. Downregulation of Dock1 and Elmo1 suppresses the migration and invasion abilities of MDA-MB-231 cells. (A) Migration and (B) invasion assays were performed to evaluate the migration and invasion abilities of MDA-MB-231 cells, MDA-MB-231 cells transfected with an empty vector, MDA-MB-231 cells transfected with si-Dock1 and MDA-MB-231 cells transfected with si-Elmol. ${ }^{*} \mathrm{P}<0.05,{ }^{* *} \mathrm{P}<0.01$ and ${ }^{* * *} \mathrm{P}<0.001$ vs. NC. Dock1, dedicator of cytokinesis 1 ; Elmol, engulfment and cell motility 1; si, small interfering RNA; NC, negative control.

A
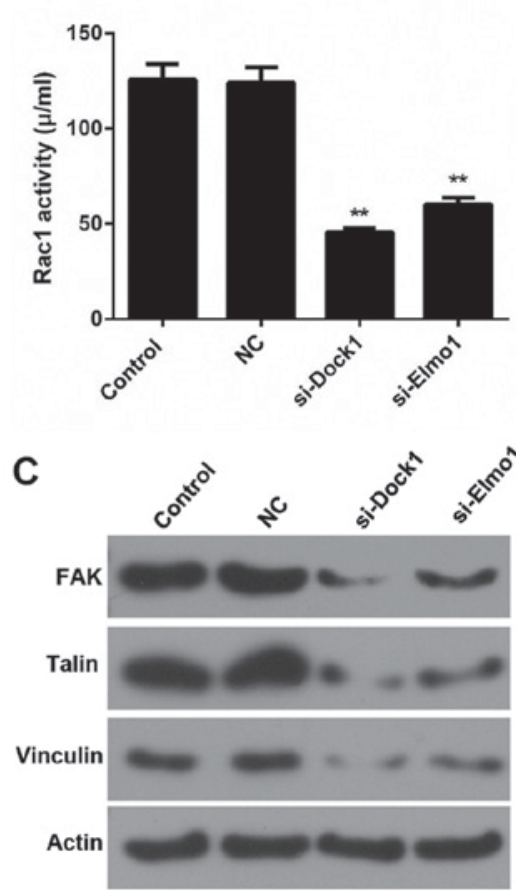

B
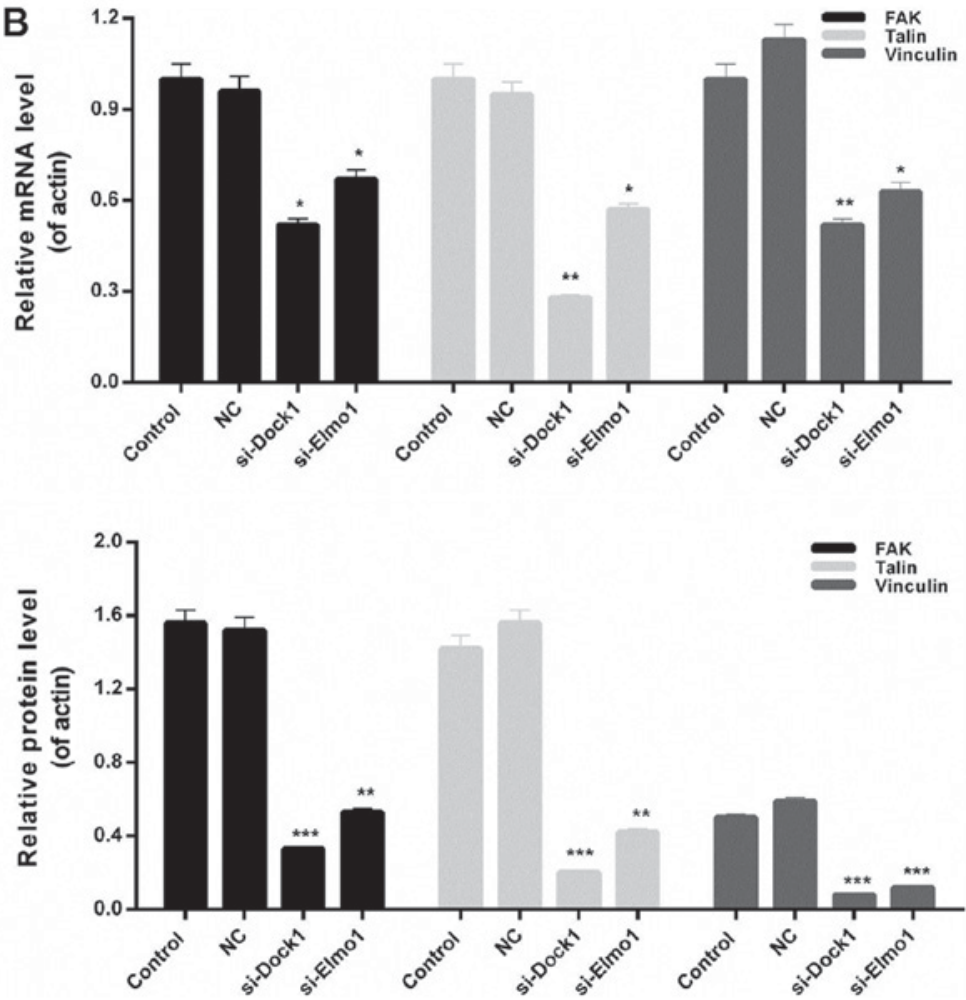

Figure 4. Downregulation of Dock1 and Elmo1 reduces Rac1 activity and the expression of migration-associated proteins in MDA-MB-231 cells. (A) A Rac activity assay was performed to evaluate the Rac1 activity of MDA-MB-231 cells. (B) Reverse transcription-quantitative polymerase chain reaction and (C) western blot analysis assays were performed to measure the expression levels of FAK, Talin and Vinculin in MDA-MB-231 cells, MDA-MB-231 cells transfected with an empty vector, MDA-MB-231 cells transfected with si-Dock1 and MDA-MB-231 cells transfected with si-Elmo1. ${ }^{*} \mathrm{P}<0.05$, ${ }^{* *} \mathrm{P}<0.01$ and ${ }^{* * *} \mathrm{P}<0.001$ vs. NC. Dock1, dedicator of cytokinesis 1; Elmo1, engulfment and cell motility 1; Rac1, Ras-related C3 botulinum toxin substrate 1; FAK, focal adhesion kinase; si, small interfering RNA; NC, negative control. 

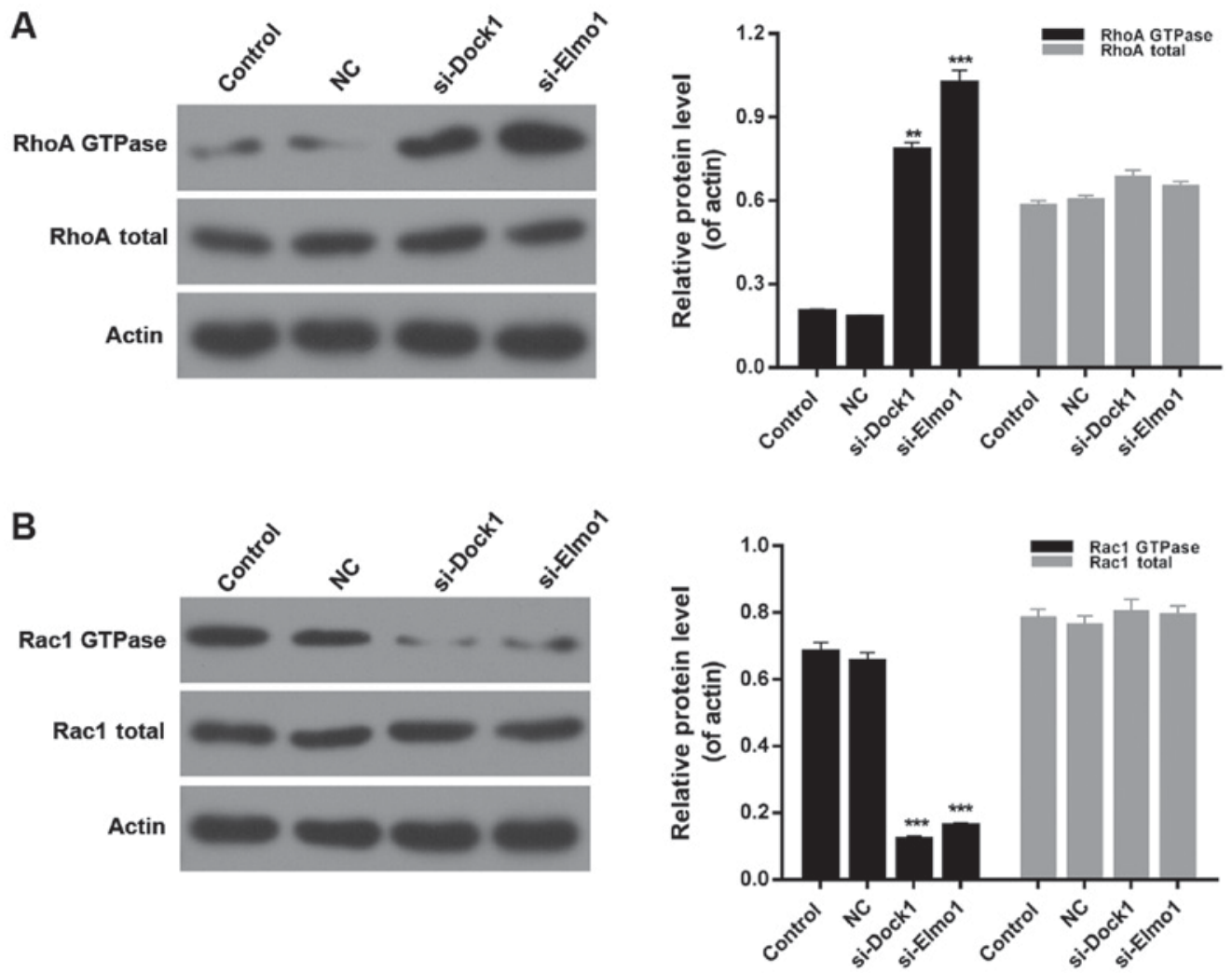

Figure 5. Downregulation of Dock1 and Elmo1 affected the RhoA/Rac1 pathway. Western blot analyses were performed to evaluate the expression levels of (A) RhoA QTPase and RhoA total, and (B) Rac1 GTPase and Rac1 total in MDA-MB-231 cells, MDA-MB-231 cells transfected with an empty vector, MDA-MB-231 cells transfected with si-Dock1 and MDA-MB-231 cells transfected with si-Elmo1. ${ }^{* *} \mathrm{P}<0.01$ and ${ }^{* * *} \mathrm{P}<0.001$ vs. NC. Dock1, dedicator of cytokinesis 1; Elmo1, engulfment and cell motility 1; RhoA, Ras homolog gene family, member A; Rac1, Ras-related C3 botulinum toxin substrate 1; si, small interfering RNA; NC, negative control.

Additionally, the present study also evaluated the Rac1 activity of MDA-MB-231 cells transfected with si-Dock1 and si-Elmol. The results revealed that the downregulation of Dock1 and Elmo1 significantly reduced the proliferation ability and Rac1 activity of MDA-MB-231 cells. Furthermore, the impact of Dock1 and Elmol silencing on the migration and invasion of MDA-MB-231 cells was investigated in the present study. Based on previous reports, the expression levels in MDA-MB-231 cells of several migration-associated proteins, including FAK, Talin and Vinculin, were assessed (30-32). The data revealed that the downregulation of Dock1 and Elmo1 markedly reduced the expression levels of FAK, Talin and Vinculin in MDA-MB-231 cells. Therefore, it was confirmed that the downregulation of Dock1 and Elmo1 may decrease the migration and invasion abilities of MDA-MB-231 cells by regulating FAK, Talin and Vinculin expression.

Previous studies have demonstrated that the RhoA/Rac1 pathway is involved in the migration and invasion of tumor cells (33-36). In the migration and invasion of breast cancer cells, the RhoA/Racl pathway also serves vital functions (36-39). Nonetheless, in TNBC epithelial cells, the role of this pivotal, migration-associated signaling pathway remains unclear. Therefore, the present study measured the expression levels of RhoA GTPase, total RhoA, Racl GTPase and total Rac1 in MDA-MB-231 cells from each treatment group, and revealed that the downregulation of Dock1 and Elmo1 markedly enhanced the expression of RhoA GTPase, while reducing the expression level of Rac1 GTPase. Additionally, there was no significant difference in the total RhoA and Rac1 expression between MDA-MB-231 cells from each treatment group. Therefore, these results confirmed that the downregulation of Dock1 and Elmo1 affected the RhoA/Rac1 pathway in MDA-MB-231 cells.

Taken together, the results of the present study demonstrated that the downregulation of Dock1 and Elmol decreased the migration and invasion abilities of MDA-MB-231 cells by affecting the RhoA/Racl pathway. These results provided novel insights into the pathogenesis of TMBC, giving rise to novel possibilities for TNBC therapy.

In summary, the present study demonstrates that the downregulation of Dock1 and Elmo1 decreased the migration and invasion abilities of TNBC epithelial cells through the RhoA/Racl pathway. These results offer crucial insight into the mechanisms of Dock1 and Elmo1 in TNBC epithelial cells. The observed effects of Dock1 and Elmo1 on the migration and invasion of TNBC epithelial cells suggested that Dock1 and Elmol may be promising targets for TNBC therapies.

\section{Acknowledgements}

Not applicable.

\section{Funding}

No funding was received. 


\section{Availability of data and materials}

All data generated or analyzed during this study are included in this published article.

\section{Authors' contributions}

YL was responsible for the design of the experiment. SW and YZ were responsible for processing data. YL was a major contributor in writing the manuscript. All authors confirmed the final manuscript.

\section{Ethics approval and consent to participate}

Not applicable.

\section{Patient consent for publication}

Not applicable.

\section{Competing interests}

The authors declare that they have no competing interests.

\section{References}

1. DeSantis C, Ma J, Bryan L and Jemal A: Breast cancer statistics, 2013. CA Cancer J Clin 64: 52-62, 2014.

2. Donepudi MS, Kondapalli K, Amos SJ and Venkanteshan P: Breast cancer statistics and markers. J Cancer Res Ther 10: 506-511, 2014.

3. Weigelt B, Eberle C, Cowell CF, Ng CK and Reis-Filho JS: Metaplastic breast carcinoma: More than a special type. Nat Rev Cancer 14: 147-148, 2014.

4. Denkert C, Liedtke C, Tutt A and von Minckwitz G: Molecular alterations in triple-negative breast cancer-the road to new treatment strategies. Lancet 389: 2430-2442, 2017.

5. Bianchini G, Balko JM, Mayer IA, Sanders ME and Gianni L: Triple-negative breast cancer: Challenges and opportunities of a heterogeneous disease. Nat Rev Clin Oncol 13: 674-690, 2016.

6. Wojciak-Stothard B and Ridley AJ: Rho GTPases and the regulation of endothelial permeability. Vascul Pharmacol 39: 187-199, 2002.

7. Kamai T, Yamanishi T, Shirataki H, Takagi K, Asami H, Ito Y and Yoshida K: Overexpression of RhoA, Rac1, and Cdc42 GTPases is associated with progression in testicular cancer. Clin Cancer Res 10: 4799-4805, 2004.

8. Rihet S, Vielh P, Camonis J, Goud B, Chevillard S and de Gunzburg J: Mutation status of genes encoding RhoA, Rac1, and Cdc42 GTPases in a panel of invasive human colorectal and breast tumors. J Cancer Res Clin Oncol 127: 733-738, 2001.

9. Pan Y, Bi F, Liu N, Xue Y, Yao X, Zheng Y and Fan D: Expression of seven main Rho family members in gastric carcinoma. Biochem Biophys Res Commun 315: 686-691, 2004.

10. Simpson KJ, Dugan AS and Mercurio AM: Functional analysis of the contribution of RhoA and RhoC GTPases to invasive breast carcinoma. Cancer Res 64: 8694-8701, 2004.

11. Cote JF and Vuori K: GEF what? Dock180 and related proteins help Rac to polarize cells in new ways. Trends Cell Biol 17: 383-393, 2007.

12. Feng H,Hu B, Liu KW, Li Y,Lu X, Cheng T, Yiin JJ,Lu S, Keezer S, Fenton T, et al: Activation of Racl by Src-dependent phosphorylation of Dock180 (Y1811) mediates PDGFR $\alpha$-stimulated glioma tumorigenesis in mice and humans. J Clin Invest 121: 4670-4684, 2011.

13. Gumienny TL, Brugnera E, Tosello-Trampont AC, Kinchen JM, Haney LB, Nishiwaki K, Walk SF, Nemergut ME, Macara IG, Francis R, et al: CED-12/ELMO, a novel member of the CrkII/Dock180/Rac pathway, is required for phagocytosis and cell migration. Cell 107: 27-41, 2001.
14. Kim K, Lee J, Lee SA, Moon H, Park B, Kim D, Joo YE and Park D: Intermolecular steric inhibition of Ephexin4 is relieved by Elmo1. Sci Rep 7: 4404, 2017.

15. Hamoud N, Tran V, Croteau LP, Kania A and Cote JF: G-protein coupled receptor BAI3 promotes myoblast fusion in vertebrates. Proc Natl Acad Sci USA 111: 3745-3750, 2014.

16. Hochreiter-Hufford AE, Lee CS, Kinchen JM, Sokolowski JD, Arandjelovic S, Call JA, Klibanov AL, Yan Z, Mandell JW and Ravichandran KS: Phosphatidylserine receptor BAI1 and apoptotic cells as new promoters of myoblast fusion. Nature 497: 263-267, 2013.

17. Katoh $\mathrm{H}$ and Negishi $\mathrm{M}$ : RhoG activates Racl by direct interaction with the Dock180-binding protein Elmo. Nature 424: 461-464, 2003.

18. Park D and Ravichandran KS: Emerging roles of brain-specific angiogenesis inhibitor 1. Adv Exp Med Biol 706: 167-178, 2010.

19. Park D, Tosello-Trampont AC, Elliott MR, Lu M, Haney LB, Ma Z, Klibanov AL, Mandell JW and Ravichandran KS: BAI1 is an engulfment receptor for apoptotic cells upstream of the ELMO/Dock180/Rac module. Nature 450: 430-434, 2007.

20. Xiao Y, Peng Y, Wan J, Tang G, Chen Y, Tang J, Ye WC, Ip NY and Shi L: The atypical guanine nucleotide exchange factor Dock4 regulates neurite differentiation through modulation of Rac1 GTPase and actin dynamics. J Biol Chem 288: 20034-20045, 2013.

21. Laurin M, Huber J, Pelletier A, Houalla T, Park M, Fukui Y, Haibe-Kains B, Muller WJ and Côté JF: Rac-specific guanine nucleotide exchange factor DOCK1 is a critical regulator of HER2-mediated breast cancer metastasis. Proc Natl Acad Sci USA 110: 7434-7439, 2013.

22. Livak KJ and Schmittgen TD: Analysis of relative gene expression data using real-time quantitative PCR and the 2(-Delta Delta C(T)) Method. Methods 25: 402-408, 2001.

23. Jarzynka MJ, Hu B, Hui KM, Bar-Joseph I, Gu W, Hirose T, Haney LB, Ravichandran KS, Nishikawa R and Cheng SY: ELMO1 and Dock180, a bipartite Rac1 guanine nucleotide exchange factor, promote human glioma cell invasion. Cancer Res 67: 7203-7211, 2007.

24. Grimsley CM, Kinchen JM, Tosello-Trampont AC, Brugnera E, Haney LB, Lu M, Chen Q, Klingele D, Hengartner MO and Ravichandran KS: Dock180 and ELMO1 proteins cooperate to promote evolutionarily conserved Rac-dependent cell migration. J Biol Chem 279: 6087-6097, 2004.

25. Wang J, Dai JM, Che YL, Gao YM, Peng HJ, Liu B, Wang H and Linghu H: Elmol helps dock180 to regulate Racl activity and cell migration of ovarian cancer. Int J Gynecol Cancer 24: 844-850, 2014.

26. Balassa T, Berta G, Jakab L, Bohonyi N and Szekeres-Bartho J: The effect of the Progesterone-Induced Blocking Factor (PIBF) on E-cadherin expression, cell motility and invasion of primary tumour cell lines. J Reprod Immunol 125: 8-15, 2018.

27. Sanders MA, Ampasala D and Basson MD: DOCK 5 and DOCK 1 regulate Caco-2 intestinal epithelial cell spreading and migration on collagen IV. J Biol Chem 284: 27-35, 2009.

28. Shi L, Zhang B, Sun X, Zhang X, Lv S, Li H, Wang X, Zhao C, Zhang H, Xie X, et al: CC chemokine ligand 18 (CCL18) promotes migration and invasion of lung cancer cells by binding to Nir1 through Nir1-ELMO1/DOC180 signaling pathway. Mol Carcinog 55: 2051-2062, 2016.

29. Tajiri H, Uruno T, Shirai T, Takaya D, Matsunaga S, Setoyama D, Watanabe M, Kukimoto-Niino M, Oisaki K, Ushijima M, et al: Targeting ras-driven cancer cell survival and invasion through selective inhibition of DOCK1. Cell Rep 19: 969-980, 2017.

30. Gu S, Papadopoulou N, Nasir O, Föller M, Alevizopoulos K, Lang F and Stournaras C: Activation of membrane androgen receptors in colon cancer inhibits the prosurvival signals Akt/bad in vitro and in vivo and blocks migration via vinculin/actin signaling. Mol Med 17: 48-58, 2011.

31. Huang C, Rajfur Z, Yousefi N, Chen Z, Jacobson K and Ginsberg MH: Talin phosphorylation by $\mathrm{Cdk} 5$ regulates Smurf1-mediated talin head ubiquitylation and cell migration. Nat Cell Biol 11: 624-630, 2009.

32. Sieg DJ, Hauck CR, Ilic D, Klingbeil CK, Schaefer E, Damsky CH and Schlaepfer DD: FAK integrates growth-factor and integrin signals to promote cell migration. Nat Cell Biol 2: 249-256, 2000 .

33. Dreissigacker U, Mueller MS, Unger M, Siegert P, Genze F, Gierschik P and Giehl K: Oncogenic K-Ras down-regulates Racl and RhoA activity and enhances migration and invasion of pancreatic carcinoma cells through activation of p38. Cell Signal 18: 1156-1168, 2006. 
34. Gulhati P, Bowen KA, Liu J, Stevens PD, Rychahou PG, Chen M, Lee EY, Weiss HL, O'Connor KL, Gao T and Evers BM: mTORC1 and mTORC2 regulate EMT, motility, and metastasis of colorectal cancer via RhoA and Racl signaling pathways. Cancer Res 71: 3246-3256, 2011.

35. Parri $\mathrm{M}$ and Chiarugi P: Rac and Rho GTPases in cancer cell motility control. Cell Commun Signal 8: 23, 2010.

36. Zhao Y, Li J, Xing Y, Wang J, Lu C, Xin X and Geng M: $\mathrm{N}$-acetylglucosaminyltransferase $\mathrm{V}$ mediates cell migration and invasion of mouse mammary tumor cells 4TO7 via RhoA and Rac1 signaling pathway. Mol Cell Biochem 309: 199-208, 2008.

37. BaugherPJ,Krishnamoorthy L,Price JEand Dharmawardhane SF: Rac1 and Rac3 isoform activation is involved in the invasive and metastatic phenotype of human breast cancer cells. Breast Cancer Res 7: R965-R974, 2005.
38. Bourguignon LY, Zhu H, Shao L and Chen YW: CD44 interaction with tiam1 promotes Rac1 signaling and hyaluronic acid-mediated breast tumor cell migration. J Biol Chem 275: $1829-1838,2000$

39. Burbelo P, Wellstein A and Pestell RG: Altered Rho GTPase signaling pathways in breast cancer cells. Breast Cancer Res Treat 84: 43-48, 2004.

cc) (i) (-) This work is licensed under a Creative Commons EY No No Attribution-NonCommercial-NoDerivatives 4.0 International (CC BY-NC-ND 4.0) License. 